\title{
Characterization and Hydrodesulfurization Activity Studies of Unpromoted Molybdenum Sulfides Prepared by Elemental Solid State Reaction
}

\author{
Jim Lindner, ${ }^{1}$ Amit Sachdev, ${ }^{2}$ Johannes Schwank, and Maria Villa-Garcia ${ }^{3}$ \\ Department of Chemical Engineering, The University of Michigan, Ann Arbor, Michigan 48109-2136
}

Received July 8, 1991; revised March 31, 1992

\begin{abstract}
Solid state reactions of elemental molybdenum and sulfur were used to synthesize unpromoted, model HDS catalysts. The samples studied had synthesis stoichiometries of $\operatorname{MoS}_{2}, \operatorname{MoS}_{1.95}$, and $\mathrm{MoS}_{1.975}$. Catalytic activity for the hydrodesulfurization of thiophene was tested in a flow reactor at temperatures ranging from 523 to $673 \mathrm{~K}$ and $1 \mathrm{~atm}$ of pressure. Characterization of these materials was carried out using X-ray diffraction, electron microscopy, $\mathrm{O}_{2}$ and $\mathrm{CO}$ chemisorption, and $\mathrm{X}$ ray photoelectron spectroscopy. Our activity measurements indicate that increased HDS activity coincides with the presence of a nonstoichiometric molybdenum sulfide phase as determined by XRD and electron microscopy. The chemisorption studies revealed that a small reduction in a catalyst's sulfur content could cause a 20 -fold increase in BET surface area and a 50 -fold increase in $\mathrm{O}_{2}$ or $\mathrm{CO}$ uptake. Normalization of the HDS activity based on chemisorption data using $\mathrm{O}_{2}$ and $\mathrm{CO}$ as probe molecules proved to be a meaningful method for assessing HDS activities. On the stoichiometric $\mathrm{MoS}_{2}$ sample, XPS showed the presence of significant amounts of surface oxygen even after prolonged treatment in $\mathrm{H}_{2} / \mathrm{H}_{2} \mathrm{~S}$ while surface oxygen was completely removed from the nonstoichiometric samples after reduction under similar conditions. This resulted in greater Mo and $S$ concentrations at the surface of the nonstoichiometric materials, improved the surface sulfiding, and may be linked to higher HDS activity. Additional work is necessary to establish the link between the observed increased in catalytic activity, increased $\mathrm{H}_{2}$ dissociation capability, and the specific surface reaction mechanism. 1992 Academic Press, Inc.
\end{abstract}

\section{INTRODUCTION}

The role of the promoter atom in hydrodesulfurization (HDS) catalysis has been the focus of intense study during the past 15 years as different hypotheses have been proposed to explain the observed catalytic activity. The exact structure of the catalytic HDS centers is still under discussion and the subject of ongoing research. Numerous models have been proposed including the

${ }^{1}$ Now at the U.S. Environmental Protection Agency Motor Vehicle Emissions Laboratory, 2565 Plymouth Road, Ann Arbor, Michigan 48105.

2 Now at the Department of Chemical Engineering, University of Illinois, Urbana, Illinois 61801.

${ }^{3}$ Now at the Departmento de Química Organometálica, Facultad de Química, Universidad de Oviedo, Oviedo 33071, Spain. monolayer model $(l-3)$, the intercalation model $(4,5)$, the contact synergy model $(6-8)$, and the CoMoS model $(9,10)$. Harris and Chianelli attributed Group VIII promotion to an electronic effect (11). In a refinement of the contact synergy model, it was proposed that the role of Group VIII promoters is mainly to stabilize the dispersion of very small particles of $\mathrm{MoS}_{2}(12,13)$. Vissers et al. (14) have indicated that the active site for HDS may actually be the Co promoter itself and that the molybdenum sulfide phase serves primarily as a secondary support. Recent Mössbauer emission spectroscopy of carbon supported Co and CoMo catalysts $(15,16)$ have supported this concept.

To simplify the catalytic system and reduce the number of variables introduced 
during a traditional HDS catalyst synthesis, we began studying catalysts prepared by solid state synthesis. The solid state approach helps circumvent some of the difficulties introduced during the traditional synthesis techniques such as comaceration, homogeneous sulfide precipitation, or coprecipitation. This is achieved by allowing the levels of molybdenum, sulfur, and promoter species to be set a priori at a known value and then significantly reducing the number of steps and phase changes between the initial mixing of the starting materials and the formation of the final catalytic phase. Not only did the solid state synthesis approach allow us to set the elemental compositions of our materials at the outset of our experiments, but by choosing to examine only bulk, unsupported materials we further simplified the system. This aided our characterization efforts by both removing any possible support interactions and increasing the relative abundance of the molybdenum and promoter atoms. Other HDS research conducted in our laboratory has employed this solid state approach to catalysts promoted with $\mathrm{Fe}$ or $\mathrm{Co}$ and provided insight into the structure-activity relationships of these promoted samples (17-19).

Our earlier work suggested that in the model solid state catalyst system a primary role of the promoter atoms was to scavenge sulfur during catalyst synthesis, thereby enhancing the formation of nonstoichiometric molybdenum sulfide phases with increased HDS activity $(17-19)$. Having seen the link between nonstoichiometry and the scavenging behavior of the promoter atom, we proposed to further simplify our system by removing the promoter atom from the synthesis step and working with only molybdenum and various levels of sulfur. These experiments allowed us to determine the effect of different degrees of sulfur deficiency on catalyst microstructure, adsorption characteristics, and observed HDS activity. Since sulfur vacancies have been postulated to be a possible active center in HDS catalysis, this work focused on unpromoted, sulfur-deficient $\mathrm{MoS}_{2}$, or $\mathrm{MoS}_{2-x}$. This current paper reports the results of these findings using a stoichiometric $\mathrm{MoS}_{2}$ sample as well as two nonstoichiometric samples, $\mathrm{MoS}_{1.975}$ and $\mathrm{MoS}_{1.95}$.

\section{EXPERIMENTAL}

\section{Catalyst Synthesis and}

\section{Activity Measurements}

The solid state catalysts were prepared by combining elemental Mo and $\mathrm{S}$ in the desired stoichiometric amounts, evacuating to $0.1 \mathrm{~Pa}$ in a quartz tube, sealing, and then heating to $783 \mathrm{~K}$ in vacuum for $24 \mathrm{hr}$. Additional details of this synthesis have been presented previously $(17-19)$. It should be remembered that the stoichiometries referred to throughout this manuscript reflect these synthesis stoichiometries and not those of the catalysts after pretreatment or HDS reaction. The catalytic activity for the HDS of thiophene was measured in a simple flow reactor. Reaction temperatures ranged from 523 to $673 \mathrm{~K}$ and the pressure was held constant at one atmosphere. The powdered catalyst $(0.25-0.35 \mathrm{~g})$ was loaded into a quartz reactor and pretreated in flowing $\mathrm{He}$ $(20 \mathrm{ml} / \mathrm{min}$ ) at $673 \mathrm{~K}$ for $30 \mathrm{~min}$. The temperature was then lowered to the desired reaction temperatures and the He flow was replaced by $2.7 \%$ by volume thiophene in $\mathrm{H}_{2}$ $(10 \mathrm{ml} / \mathrm{min})$. The reactor effluent was analyzed by a gas chromatograph equipped with a thermal conductivity detector. Activity measurements were used here as a characterization tool with the intent to establish relative activity comparisons among the three samples rather than to develop a rate law with precise rate constants. In several instances, the overall thiophene conversions exceeded the differential regime. Therefore, we report our activities in terms of "pseudoturnover frequencies," to indicate that they do not necessarily represent the true differential rates. Additional details may be found in the literature $(17-19)$.

\section{Catalyst Characterization}

X-ray diffraction patterns of the three samples were taken on a Rigaku diffrac- 
tometer with $\mathrm{Cu} K \alpha$ radiation operated at 15 $\mathrm{kV}$ and $100 \mathrm{~mA}$ using a step size of $0.02 \theta$ degrees. Collection times ranged from 5 to $10 \mathrm{~min}$. Samples were prepared by grinding the synthesized powders and mounting them on a glass cover slip using methanol as a wetting agent. The surface areas of the freshly prepared catalysts were determined by the BET method using a Monosorb Quantachrome single point instrument with nitrogen as the adsorbate. Sample pretreatment was performed by outgassing 250 $500 \mathrm{mg}$ of sample for $1 \mathrm{hr}$ in flowing $\mathrm{N}_{2} / \mathrm{He}$ at $400 \mathrm{~K}$.

Chemisorption measurements were made with the pulse technique using a Quantasorb Sorption System (QS-17). This apparatus was equipped with a thermal conductivity detector that sensed the quantity of nonadsorbed species flowing through the sample loop. The amount of adsorbed species was then easily calculated since the original amount injected into the system was known. A four-way valve allowed the pre-treatment gas to be switched to the chemisorption mixture without exposing the sample to air. Sample sizes were $200-300 \mathrm{mg}$, and the injections used were $1 \mathrm{~cm}^{3}$. The gas mixtures used for chemisorption consisted of $9.98 \%$ $\mathrm{O}_{2}$ in $\mathrm{He}$ and $9.96 \% \mathrm{CO}$ in $\mathrm{He}$. Prior to all measurements, the sample was reduced in pure $\mathrm{H}_{2}(60 \mathrm{cc} / \mathrm{min})$ at $573 \mathrm{~K}$ for a minimum of $8 \mathrm{hr}$. After reduction, the sample was cooled to room temperature in flowing $\mathrm{He}$ $(60 \mathrm{cc} / \mathrm{min})$ for $45 \mathrm{~min}$ and then placed in a $298 \mathrm{~K}$ constant temperature bath.

High-resolution electron microscopy was done using a JEOL $4000 \mathrm{EX}$ equipped with a $\mathrm{LaB}_{6}$ filament. An accelerating voltage of $400 \mathrm{kV}$ was used and no specimen damage from beam irradiation was detected. At this voltage the point-to-point resolution for the instrument was $1.8 \AA$. Specimen preparation consisted simply of depositing a few drops of an isopropanol-suspended catalyst powder on a holey carbon-covered copper grid.

X-ray photoelectron (XPS) work was done on a Perkin-Elmer 5400 Series instrument using an $\mathrm{Al}$ anode with a characteristic wavelength of $1486.6 \mathrm{eV}$ operating at $15 \mathrm{kV}$ and $300 \mathrm{~W}$. An in situ reactor allowed samples to be treated in a $2 \% \mathrm{H}_{2} \mathrm{~S} / \mathrm{H}_{2}$ mixture $\left(20 \mathrm{~cm}^{3} / \mathrm{min}\right)$ at $673 \mathrm{~K}(2-\mathrm{hr}$ treatment time) and then analyzed without air exposure. The vacuum during transfer from the reactor to the analysis chamber was estimated to be $10^{-7}$ Torr $\left(1\right.$ Torr $=133.3 \mathrm{~N} \mathrm{~m}^{-2}$ ) in the worst case, while the vacuum in the chamber was maintained at $10^{-9}$ Torr during an analysis. Binding energies were referenced to the adventitious $\mathrm{C} 1 s$ peak at $284.6 \mathrm{eV}$, which was found to be present in small amounts even after reactor treatment. In semiconducting samples such as $\operatorname{MoS}_{x}$, it is possible that sulfiding alters the sample charging characteristics, and this would introduce an additional source of experimental error into comparisons of absolute values of binding energies before and after sulfiding. An alternative way to assess changes in chemical state would be to look at the relative energy differences $(\Delta \mathrm{BE})$ between Mo $3 d_{3 / 2}$ and $\mathrm{S} 2 p_{1 / 2}$. Data analysis was performed using the PHI computer and associated software. Peak area calculations were accomplished by parabolic interpolation with the areas normalized by both the size of the unit step and time of acquisition. Smoothing of the spectra could be done if desired using the Savitzky-Golay convolution algorithm, which may be thought of as an expanded calculation of a moving average. Curve fitting routines were performed using linear background subtraction. The fitting algorithm obtains a weighted leastsquares fit of the data values $\left(X_{i}, Y_{i}\right)$ to a specified function $\left[F\left(X_{i}, P_{j}\right)\right]$ by stepwise Gauss-Newton iterations on the $P_{j}$ parameters. The function $[F(X, P)]$ is of the form

$$
F(x, P)=\sum_{k=1}^{n} A_{k}(X, P),
$$

where $A_{k}$ are functions describing a band. Goodness of fit is determined by minimizing the error mean square, given as follows:

$$
s^{2}=\frac{1}{(n-m)} \sum_{i=1}^{n} W_{i}\left[\left(X_{i}, P_{j}\right)-Y_{i}\right]^{2} .
$$




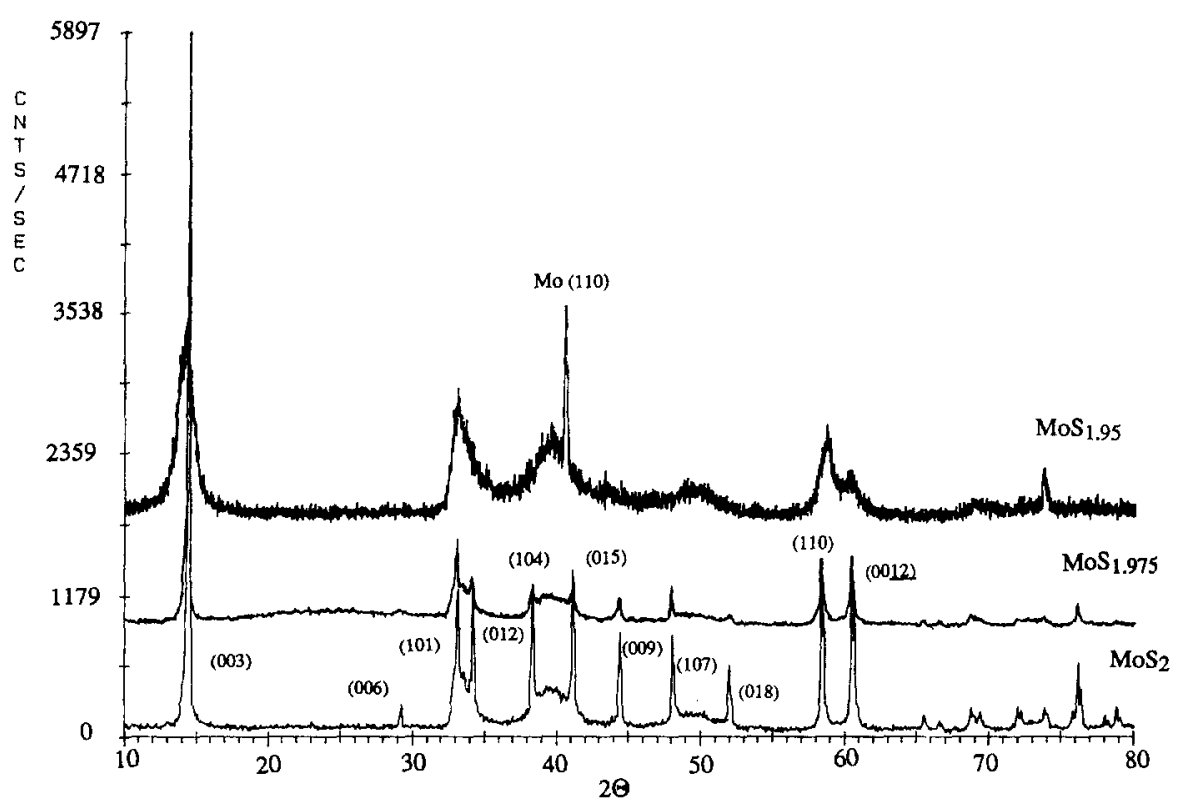

FIG. 1. X-ray diffraction patterns of $\mathrm{MoS}_{2-x}$ samples.

\section{RESULTS AND DISCUSSION}

\section{$X$-ray Diffraction and}

\section{Electron Microscopy}

Figure 1 provides the characteristic XRD patterns of $\mathrm{MoS}_{2}$ and the two nonstoichiometric samples. The crystalline $\mathrm{MoS}_{2}$ sample can be identified as rhombohedral molybdenite $3 \mathrm{R}$. However, it can be seen that even a slight reduction in sulfur content results in an immediate change readily visible in XRD, as the pattern of $\mathrm{MoS}_{1.975}$ differs noticeably from that of $\mathrm{MoS}_{2}$. The respective stoichiometries may be translated into weight percent of sulfur removed in the synthesis step. If this is done and stoichiometric $\mathrm{MoS}_{2}$ assigned a value of $100 \%$, then $\mathrm{MoS}_{1.975}$ contains $99.4 \%$ of the sulfur in $\mathrm{MoS}_{2}$, and $\mathrm{MoS}_{1.95}, 98.7 \%$. Hence, the crystal structure is extremely sensitive to slight changes in composition within this narrow range. An earlier study conducted by Liang et al. (20) modeled the XRD patterns of poorly crystalline (px) $\mathrm{MoS}_{2}$ and compared the computer simulated patterns to actual experimental XRD patterns. Unlike our crystalline rhombohedral $\mathrm{MoS}_{2}$, the well crystalline sample of Liang et al. was hexagonal; however, loss of crystallinity of their samples resulted in XRD traces very similar to those displayed by our $\operatorname{MoS}_{1.95}$ and $\mathrm{MoS}_{1.975}$ samples. Specifically, the peaks contained in the $2 \theta$ regions of $33^{\circ}, 40^{\circ}$, and $60^{\circ}$ became quite diffuse and lost intensity. Liang et al. found that these regions of the XRD pattern carried important structural information regarding the defect nature of the sample, and in particular could be generated computationally by an arbitrary rotation of the molybdenum sulfide layers about the $c$-axis. Liang et al. concluded that the observed diffuse XRD pattern of $\mathrm{px}-\mathrm{MoS}_{2}$ was due primarily to stacking disorder in the $c$ direction. Our results indicate that our rhombohedral $\mathrm{MoS}_{2}$ behaves quite similarly as it loses crystalline order.

The structural changes induced by the sulfur deficiency, which were quite apparent in XRD, may also be detected by HREM. The images taken of all (003) lattice fringes for each sample were identical, as would be expected from the XRD patterns that showed no change in the (003) reflection as the sulfur content was decreased. However, Fig. 2 

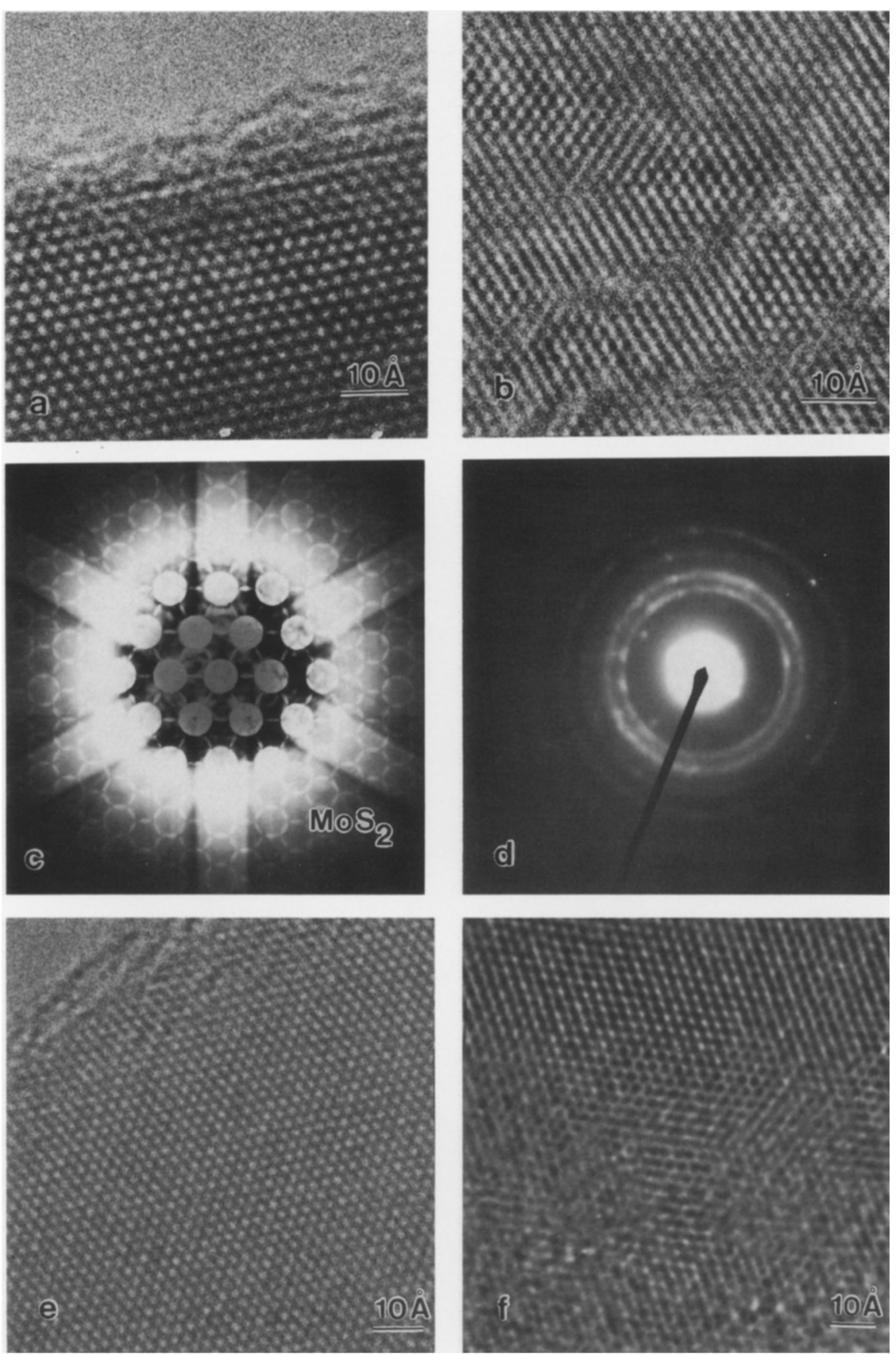

Fig. 2. (a) HREM image of $\mathrm{MOS}_{2}$, (b) HREM image of $\mathrm{MoS}_{1.95}$, (c) CBED pattern of MoS, , (d) SAED ring pattern characteristic of $\mathrm{MoS}_{1.95}$, (e) well crystalline region in $\mathrm{MoS}_{\mathrm{l.975}}$, and (f) defect region in $\mathrm{MoS}_{1.975}$. 
provides HREM images of the (101) lattice fringe, roughly corresponding to a 2.7 - $\AA$ lattice spacing. The (101) plane is an example of an "edge plane." A schematic drawing of basal and edge planes can be found elsewhere $(19)$. The well-ordered, defect free nature of $\mathrm{MoS}_{2}$ (Fig. 2a) is readily apparent as all regions imaged in this sample display well-defined structures. The images of the $2.7 \AA$ (101) lattice fringes in this micrograph correspond to the $33^{\circ} 2 \theta$ region in Figure 1 . These micrographs stand in striking contrast to the characteristic imperfect, multitextured structural arrangements exhibited by the same (101) plane in the micrograph of $\mathrm{MoS}_{1.95}$ (Fig. 2b). This point is also demonstrated in electron diffraction patterns, as convergent beam electron diffraction (CBED) patterns were obtainable in the case of $\mathrm{MoS}_{2}$ (Fig. 2c), while for $\mathrm{MoS}_{1.95}$ only ring patterns (Fig. $2 \mathrm{~d}$ ) were observed. The presence of the ring patterns confirms that the sample lacks long range order and may be considered to be polycrystalline. Hence, the sample illustrated in Fig. 2 b possesses a less ordered surface than that illustrated in Fig. 2a. The existence of well-defined CBED patterns in the case of the $\mathrm{MoS}_{2}$ bears testimony to the long range order and structure also illustrated in sharp XRD peaks and in the clean, neatly stacked atomic structures pictured in HREM. The significance of the CBED images in this context is that such diffraction patterns require a nearly perfect crystal, on the order of hundreds of square angstroms in area. High resolution images of $\mathrm{MoS}_{1.975}$ (Fig. 2e) reveal that it also possesses the well-defined crystal framework displayed by $\mathrm{MoS}_{2}$ in the (101) 2.7- $\AA$ fringe; however, it was not possible to acquire CBED patterns, indicating that although the localized atomic arrangement is quite similar to that of $\mathrm{MoS}_{2}$, it does not extend over as large an area. Our inability to obtain CBED patterns for this sample might also be explained by the loss of stacking order in the $c$ direction as described in the previous paragraph. All diffraction patterns obtained from the $\mathrm{MoS}_{1.975}$ sample re-
TABLE 1

$\mathrm{MoS}_{2-x}$ Surface Areas and Adsorption Characteristics

\begin{tabular}{lccc}
\hline & $\begin{array}{c}\mathrm{BET} \\
\left(\mathrm{m}^{2} / \mathrm{g}\right)\end{array}$ & $\begin{array}{c}\mathrm{O}_{2} \\
(\mu \mathrm{mole} / \mathrm{g})\end{array}$ & $\begin{array}{c}\mathrm{CO} \\
(\mu \mathrm{mole} / \mathrm{g})\end{array}$ \\
\hline $\mathrm{MoS}_{2}$ & 1.0 & 1.11 & 0.43 \\
$\operatorname{MoS}_{\mathrm{I} .975}$ & 0.89 & 1.10 & 0.58 \\
$\operatorname{MoS}_{1.95}$ & 20.0 & 51.8 & 27.2 \\
\hline
\end{tabular}

sembled the diffuse rings of $\mathrm{MoS}_{1.95}$ pictured in Figure 5.2d. If a great many individual particles were examined in a very thorough and painstaking fashion, it became evident that there were some regions containing a high defect concentration in the $\mathrm{MoS}_{1.975}$ sample (Fig. 2f). Hence, the $\mathrm{MoS}_{1.975}$ species does in fact display the signature characteristics of both well crystalline, stoichiometric $\mathrm{MoS}_{2}$ and polycrystalline, defectrich $\mathrm{MoS}_{1.95}$ in localized areas. However, it must be emphasized that most regions examined in $\mathrm{MoS}_{1.975}$ appeared well-ordered locally in the (101) plane as in the case of $\mathrm{MoS}_{2}$, but apparently lacked long range stacking order in the $c$ direction.

\section{Chemisorption and \\ Activity Measurements}

The results of the adsorption studies are summarized in Table 1. Given the similarities of the $\mathrm{MoS}_{2}$ and $\mathrm{MoS}_{1.975}$ illustrated in the HREM investigation, it is not surprising to see the close agreement of the adsorption capability for these two materials, since it is generally accepted that $\mathrm{O}_{2}$ and $\mathrm{CO}$ adsorb on edge positions $(21-25)$. However, the large differences in chemisorption and BET area caused by a further slight reduction in sulfur content to the $\mathrm{MoS}_{1.95}$ material are remarkable, as the surface area increases by a factor of 20 , while chemisorption for both $\mathrm{O}_{2}$ and $\mathrm{CO}$ increases by a factor of 50 .

The results of the activity measurements appear in Fig. 3, which shows Arrhenius plots of the natural log of the pseudoturnover frequency (PTOF) vs. $1 / T$. The PTOF is a normalized conversion based on the 


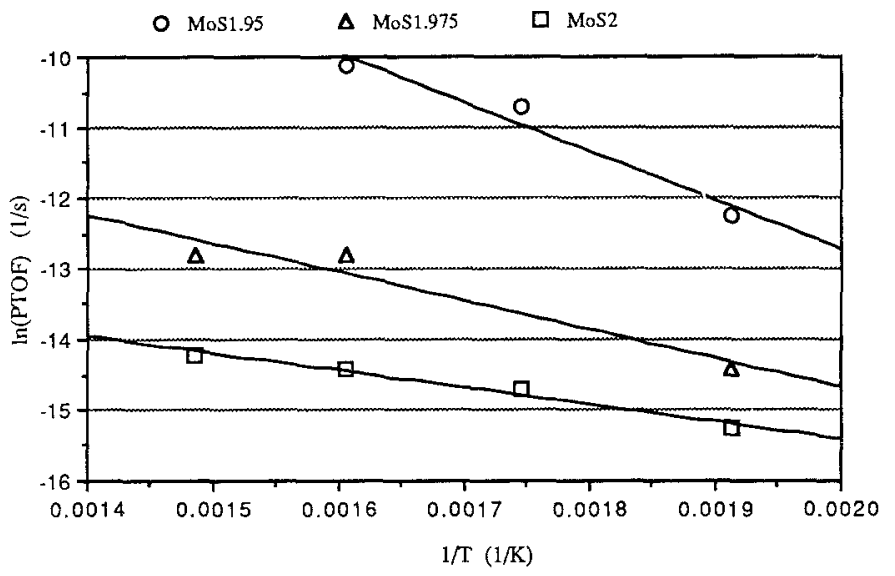

FIG. 3. Mo-normalized Arrhenius plot for thiophene HDS on $\mathrm{MoS}_{2-x}$ samples.

amount of Mo in the catalyst and has the units of $\mu$ mole of product $/(\mu$ mole Mo $\times$ time). As could be anticipated, the $\mathrm{MoS}_{1.975}$ sample with intermediate sulfur content displayed an intermediate HDS activity, while the $\mathrm{MoS}_{1.95}$ sample with relatively larger adsorptive capacity proved to be the most active. What is surprising is that given the $\mathrm{O}_{2}$ and $\mathrm{CO}$ adsorption trends, one would not anticipate that the $\mathrm{MoS}_{1.975}$ sample would possess an activity so markedly greater than that displayed by $\mathrm{MoS}_{2}$. The following hypotheses are proposed to explain this behavior; however, further experimental evidence is required before these theories gain acceptance or are refuted. From a chemisorption standpoint, it is believed that $\mathrm{O}_{2}$ is adsorbed in a dissociative fashion (2l). Therefore, it is possible that a minimum defect area or a number of defect sites situated close to each other are required to effectively adsorb $\mathrm{O}_{2}$. As we have seen from the HREM images of $\mathrm{MoS}_{1.975}$, the highly defective crystalline regions are not very numerous; therefore, this could result in the low chemisorption uptakes displayed by both $\mathrm{MoS}_{2}$ and $\mathrm{MoS}_{1.975}$. This scenario could explain the observed chemisorption trends.

If the problem is viewed in terms of HDS catalysis, we may tentatively postulate that the HDS activity differences may be indicative of different catalytic mechanisms controlling the reaction on the $\mathrm{MoS}_{2}$ and $\mathrm{MoS}_{1.975}$ surfaces, respectively. The slopes of the Arrhenius plots in Fig. 4 are different from each other, with $\mathrm{MoS}_{1.975}$ representing the average between the two other slopes. This could mean that two mechanisms coexist on the surface of this catalyst. Hypothetically, a less efficient pi-bonded thiophene scenario may sterically control the kinetics on the well crystalline $\mathrm{MoS}_{2}$, while sigmabonded thiophene may adsorb on the disordered, nonstoichiometric surfaces of $\mathrm{MoS}_{1.975}$. This could result in more catalytic sites and increased turnover. However, it again must be emphasized that these hypotheses require more detailed kinetic analyses and surface science experiments before being confirmed. Nonetheless, it is believed that these $\mathrm{MoS}_{2-x}$ samples may be well suited for performing such mechanistic studies.

Normalization of the HDS activity using the chemisorption data is depicted in Fig. 4 for $\mathrm{O}_{2}$ chemisorption and Fig. 5 for CO. In these figures the units of the normalized rates are now moles of $\mathrm{C}_{4} \mathrm{H}_{4} \mathrm{~S}$ converted per $\mu$ mole adsorbate per second. While Fig. 3 (where the activity is normalized per mole of Mo) shows 3 to 4 orders of magnitude 


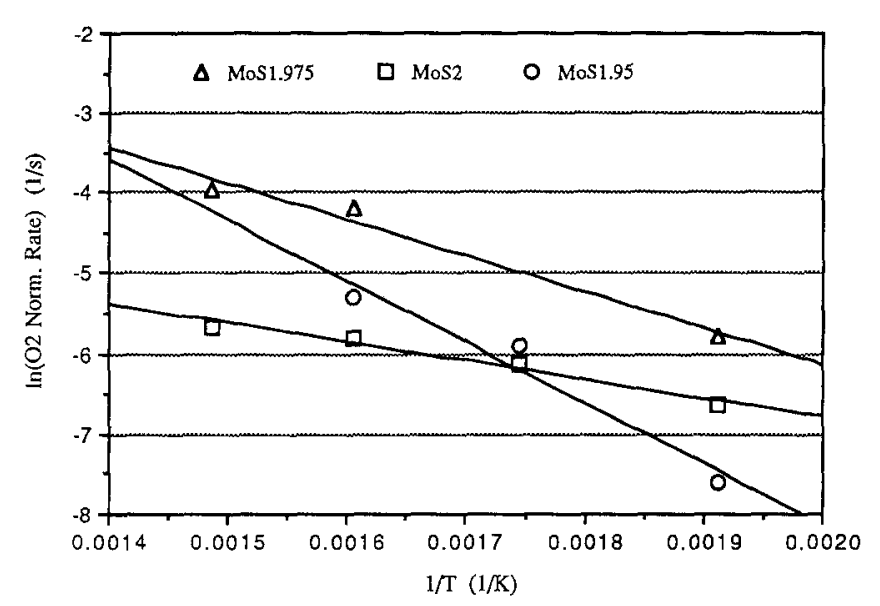

FIG. 4. $\mathrm{O}_{2}$-normalized Arrhenius plot for thiophene HDS on $\mathrm{MoS}_{2-x}$ samples.

difference in activity between $\mathrm{MoS}_{2}$ and $\mathrm{MoS}_{1.95}$, normalization using $\mathrm{O}_{2}$ or $\mathrm{CO}$ adsorption capacity brings the three catalysts within 1 or 2 orders of magnitude in activity. This suggests that normalizing the activity based on $\mathrm{O}_{2}$ and $\mathrm{CO}$ adsorption is more meaningful than merely comparing activities based on overall Mo content. It is generally well accepted that $\mathrm{O}_{2}$ and $\mathrm{CO}$ do indeed titrate the active edge positions of HDS catalysts, assuming that this edge site is involved in the rate limiting step of the reaction mechanism.

\section{$X$-ray Photoelectron Spectroscopy Studies}

XPS studies were undertaken to gain insight into the relationship between nonstoichiometry and the resulting consequences on the electronic nature of the sample. The results are summarized in Tables 2 and 3. Examination of the $\mathrm{MoS}_{2}$ sample revealed roughly a $0.4 \mathrm{eV}$ decrease in the Mo binding energy (B.E.) after $2 \mathrm{hr}$ of sulfiding treatment, suggesting a slight reduction of Mo to yield a $\mathrm{Mo}^{\partial+}$ species $(3<\partial<4)$. This behavior is typical of HDS catalysts and has been reported by other researchers (26-28). The ratio of the Mo $3 d_{5 / 2}$ to $3 d_{3 / 2}$ was 1.3 , which is slightly below the value of 1.5 predicted from quantum mechanical calculations involving the spin-orbit coupling of nonzero angular momentum orbitals (29). However, this small discrepancy in peak areas was not interpreted as cause for assuming that more than one type of Mo is present in the sample. Rather, it is more likely due to relaxation and configuration interaction effects which complicate the simple model used to predict the relative peak areas. The binding energy of the $\mathrm{S} 2 p$

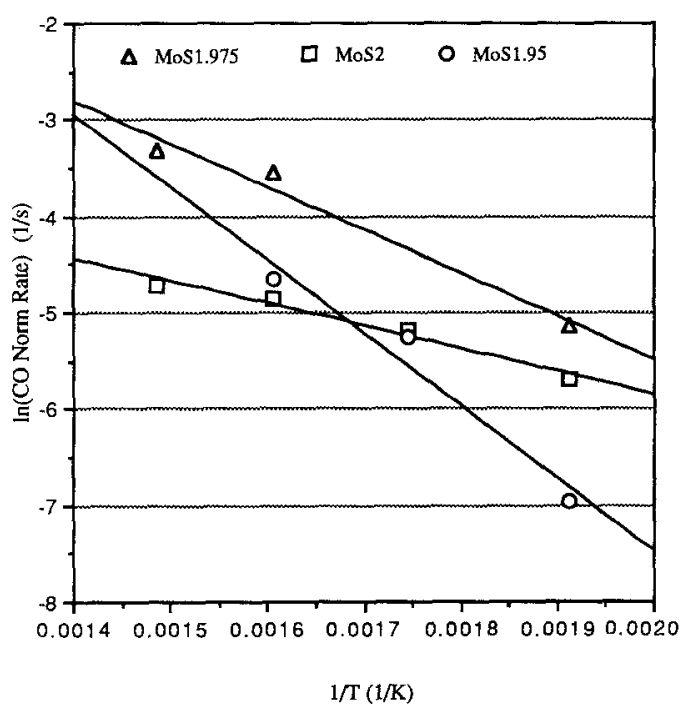

Frg. 5. CO-normalized Arrhenius plot for thiophene HDS on $\mathrm{MoS}_{2-x}$ samples. 
TABLE 2

Summary of XPS Results Before and After $2 \mathrm{hr}$ Treatment at $673 \mathrm{~K}$ in $2 \% \mathrm{H}_{2} \mathrm{~S} / \mathrm{H}_{2}$

\begin{tabular}{|c|c|c|c|c|c|c|c|}
\hline \multirow[t]{2}{*}{ Peak } & \multicolumn{2}{|c|}{$\mathrm{MoS}_{2}$} & \multicolumn{2}{|c|}{$\operatorname{MoS}_{1.975}$} & \multicolumn{3}{|c|}{$\operatorname{MoS}_{1.95}$} \\
\hline & Before & After & Before & After & & & After \\
\hline \multicolumn{8}{|l|}{ Mo $3 d_{3 / 2}$} \\
\hline $\mathrm{BE}$ & 231.8 & 231.4 & 231.6 & 232.3 & $235.9^{a}$ & 232.5 & 232.4 \\
\hline FWHM & 1.4 & 1.4 & 1.6 & 1.3 & 2.2 & 1.4 & 1.3 \\
\hline Area & 2146 & 2402 & 5854 & 12068 & 4119 & 6937 & 15659 \\
\hline \multicolumn{8}{|l|}{ Mo $3 d_{5 / 2}$} \\
\hline $\mathrm{BE}$ & 228.6 & 228.2 & 228.7 & 229.1 & 232.9 & 229.4 & 229.3 \\
\hline FWHM & 1.1 & 1.1 & 1.2 & 1.1 & 2.8 & 1.1 & 1.1 \\
\hline Area & 2789 & 3200 & 6201 & 16165 & 6983 & 8107 & 21224 \\
\hline \multicolumn{8}{|l|}{$\mathrm{S} 2 p_{1 / 2}$} \\
\hline $\mathrm{BE}$ & 162.6 & 162.1 & 162.6 & 163.0 & 163.3 & & 163.3 \\
\hline FWHM & 1.1 & 1.4 & 1.4 & 1.3 & 1.3 & & 1.3 \\
\hline Area & 751 & 1075 & 1994 & 5153 & 2777 & & 6858 \\
\hline \multicolumn{8}{|l|}{$\mathrm{S} 2 p_{3 / 2}$} \\
\hline $\mathrm{BE}$ & 161.4 & 161.0 & 161.7 & 161.9 & 162.1 & & 162.1 \\
\hline FWHM & 1.2 & 1.1 & 1.3 & 1.1 & 1.1 & & 1.1 \\
\hline Area & 1343 & 1309 & 2953 & 7149 & 3934 & & 9446 \\
\hline \multicolumn{8}{|l|}{ O $1 s$} \\
\hline $\mathrm{BE}$ & 532.5 & 532.4 & 531.1 & 531.9 & 531.4 & & - \\
\hline FWHM & 2.5 & 2.2 & 2.2 & 3.1 & 2.6 & & - \\
\hline Area & 7220 & 6691 & 12923 & 513 & 12597 & & 0 \\
\hline
\end{tabular}

${ }^{a}$ Two sets of Mo peaks were curve fitted and deconvoluted in the $\operatorname{MoS}_{1.95}$ sample before sulfiding.

doublet peak shifted to slightly lower binding energies, indicating that a reduction of the sulfur species had occurred. The energy gap separating the $2 p_{1 / 2}$ and $2 p_{3 / 2}$ orbital levels was decreased from $1.2 \mathrm{eV}$ to around 1.1 $\mathrm{eV}$ after sulfiding, while the peak area ratio, theoretically 0.5 (29), was also changed from 0.56 to 0.82 . The sulfiding treatment also effectively lowered the full width at half maximum (FWHM) of all the peaks except the low B.E. S peak, whose FWHM increased roughly $0.1 \mathrm{eV}$. This decrease in FWHM indicates an increase in the core hole relaxation time following the photoemission process, in essence reflecting the uncertainty concerning the lifetime of a core hole after photoemission. An increase in the valence electron density will enhance the probability of the core hole being filled, and this will in turn decrease the core hole lifetime, broadening the XPS peak or increasing the FWHM value. Although there was an increased surface abundance of $\mathrm{S}$ and Mo after sulfiding, as evidenced from their peak area values, the $\mathrm{O} 1 \mathrm{~S}$ peak remained at roughly $93 \%$ of its original value, even after sulfiding for $4 \mathrm{hr}$ at $673 \mathrm{~K}$. This was surprising since it was expected that the surface would be nearly completely sulfided and free of oxygen after the high temperature $\mathrm{H}_{2} \mathrm{~S} / \mathrm{H}_{2}$ treatment was performed.

XPS analysis on the $\mathrm{MoS}_{1.975}$ sample revealed some similarities, but also a number of subtle features not present in the $\mathrm{MoS}_{2}$ spectrum. The Mo exhibited a slight, but surprising, positive $0.6 \mathrm{eV}$ shift following reactor treatment, and the resulting $3 d_{5 / 2}: 3 d_{3 / 2}$ peak ratio was 1.34 . Prior to sulfiding this ratio was 1.05 , which definitely indicates the presence of another Mo species. In this case, it was most probably a molybdenum oxide phase; however, a detailed peak deconvolution and curve fit were not attempted. We noted that the $\triangle \mathrm{BE}$ between 
TABLE 3

Relative Peak Area Ratios for Molybdenum Sulfide Samples

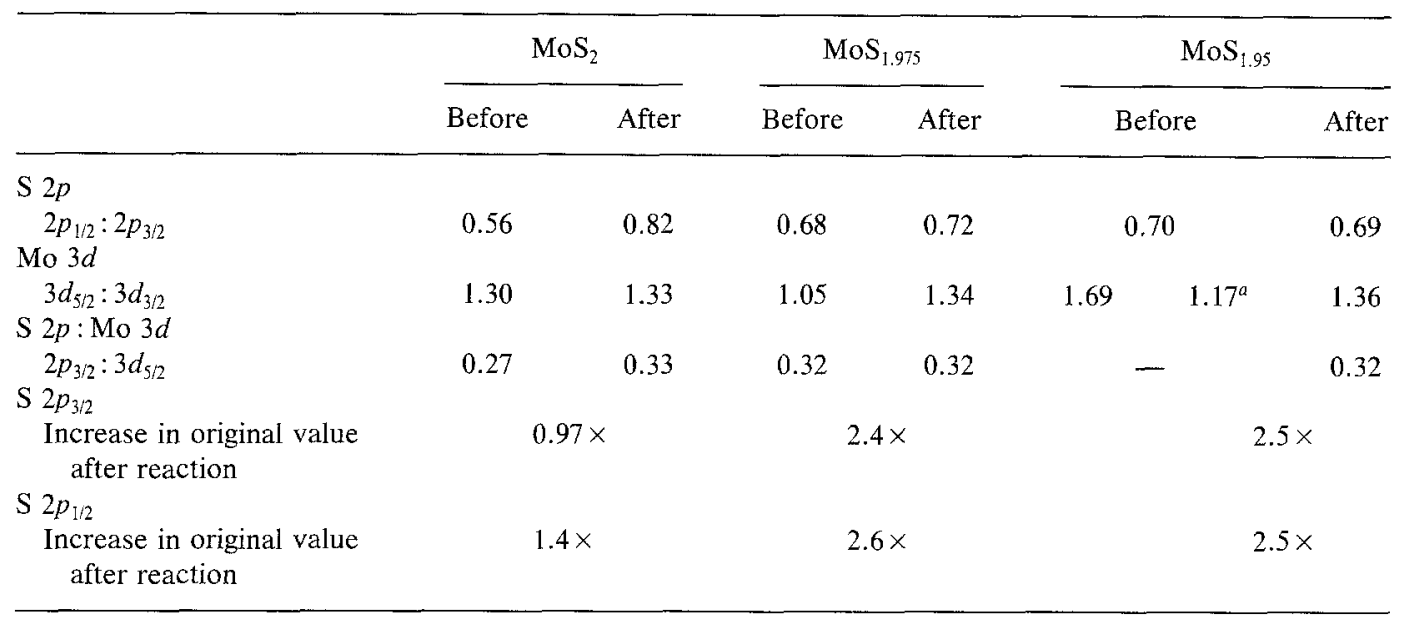

${ }^{a}$ Two sets of Mo peaks were curve fitted and deconvoluted in the $\mathrm{MoS}_{1.95}$ sample before sulfiding.

Mo $3 d_{5 / 2}$ and Mo $3 d_{3 / 2}$ exhibited a slight discrepancy, but we cannot state whether this discrepancy is of catalytic significance. The $\mathrm{S} 2 p$ peaks shifted about $0.2 \mathrm{eV}$ to higher B.E. after $\mathrm{H}_{2} \mathrm{~S} / \mathrm{H}_{2}$ exposure. Neither of these shifts to higher B.E. was anticipated. This was a reproducible result, but it seems very unlikely that a surface oxidation of the $\mathrm{MoS}_{1.975}$ occurred in the sulfiding/reducing atmosphere of the reactor chamber. It is more probable that this reflects the fact that the Mo $3 d$ peaks were not deconvoluted in the air-exposed spectrum, and this caused the reported B.E. values to be in error since they were averaged over more than one type of Mo oxide species. Therefore, it may be tacitly assumed that the Mo in the $\mathrm{MoS}_{1.975}$ sample behaved similarly to the Mo in the $\mathrm{MoS}_{1.95}$. The change in the energy gap between the $2 p_{3 / 2}$ and $2 p_{1 / 2}$ levels in the $\mathrm{MoS}_{1.975}$ catalyst behaved like that of $\mathrm{MoS}_{2}$, as the gap was slightly decreased by about $0.05 \mathrm{eV}$ after sulfiding. Such a slight change falls, of course, within the resolution limits of the spectrometer. The peak area ratio for these two orbitals did not undergo as drastic an increase; only an increase from 0.68 to 0.72 was observed. The FWHM values for all species generally decreased after $\mathrm{H}_{2} \mathrm{~S} / \mathrm{H}_{2}$ exposure, while the surface abundance of all Mo and S peaks increased. However, the most marked difference between $\mathrm{MoS}_{2}$ and $\mathrm{MoS}_{1.975}$ was in the $\mathrm{O} 1 s$ region. Ninety-six percent of the oxygen was removed from the surface of the $\mathrm{MoS}_{1.975}$ sample after $2 \mathrm{hr}$ of sulfiding, as compared to the $7 \%$ removal of oxygen from $\mathrm{MoS}_{2}$ after a 4-hr reactor treatment.

As was seen in the case for $\operatorname{MoS}_{1.975}$, the $\mathrm{MoS}_{1.95}$ sample also displayed two Mo species after air exposure; but, following sulfiding, only one species in a reduced state relative to either Mo oxide moiety prior to reactor treatment was observed. The results of the peak deconvolution and curve fit performed on the $\mathrm{MoS}_{1.95}$ spectrum appear in Table 2. After sulfiding, only the $\mathrm{Mo}^{\partial+}$ species was found to be present, as a $3 d_{5 / 2}$ : $3 d_{3 / 2}$ peak area ratio of 1.36 was obtained. The S $2 p$ peaks were lowered by about 0.06 $\mathrm{eV}$, while the $2 p_{3 / 2}: 2 p_{1 / 2}$ intensity ratio remained essentially unchanged at 0.69 . The energy difference between these two peaks was also constant at $1.2 \mathrm{eV}$. Again, sulfiding increased the surface abundance of $S$ and Mo, but now all the oxygen was removed 


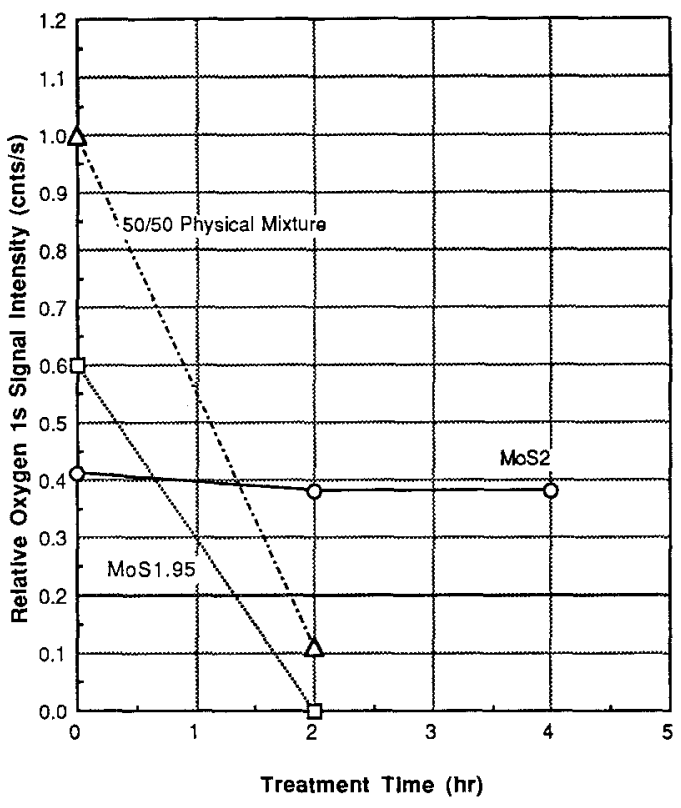

FIG. 6. Relative XPS oxygen $1 s$ signals vs. sulfiding time for $\mathrm{MoS}_{2}, \mathrm{MoS}_{1.95}$, and $50 / 50 \mathrm{MoS}_{2} / \mathrm{MoS}_{1.95}$.

from the surface during the 2-hr sulfiding treatment. However, it is noteworthy that the B.E. of the Mo $3 d$ peaks is greater than that for the $\mathrm{MoS}_{2}$ sample. This indicates that although the Mo undergoes a formal reduction during the sulfiding treatment, it is a less thorough reduction than is experienced by the Mo species in the $\mathrm{MoS}_{2}$ sample. However, one has to keep in mind that these small shifts in binding energy based on carbon reference fall well within the possible experimental error due to charging effects.

To establish if $\mathrm{H}_{2}$ dissociation was indeed linked to non-stoichiometry and the ability to remove oxygen from the surface of the sample, a physical mixture of $50 \mathrm{wt} \% \mathrm{MoS}_{2}$ and $50 \mathrm{wt} \% \mathrm{MoS}_{1.95}$ was treated in the reaction chamber at $673 \mathrm{~K}$ using the $2 \% \mathrm{H}_{2} \mathrm{~S} / \mathrm{H}_{2}$ mixture. The results of this experiment are depicted in Fig. 6, which plots the relative $\mathrm{O}_{2}$ signals normalized by the $\mathrm{O}_{2}$ signal from the untreated 50/50 $\mathrm{MoS}_{2} / \mathrm{MoS}_{1.95}$ sample against the sulfiding treatment time. As illustrated, stoichiometric $\mathrm{MoS}_{2}$ maintained a constant level of surface oxygen even after
$4 \mathrm{hr}$ of sulfiding. In contrast to this behavior, all surface oxygen was removed from the MoS $_{1.95}$ catalyst in only $2 \mathrm{hr}$ of sulfiding. Meanwhile, the normalized surface oxygen level fell from a value of 1.0 to 0.1 for the physically mixed sample in $2 \mathrm{hr}$. Therefore, roughly $90 \%$ of the oxygen originally present on the surface of the physical mixture was removed after only $2 \mathrm{hr}$ of sulfiding. These results strongly suggest that nonstoichiometry improves the dissociation of $\mathrm{H}_{2}$, thereby facilitating both the spillover of an atomic hydrogen species onto neighboring surfaces and subsequent oxygen removal. It also would appear that an increased ability to dissociate hydrogen coincides with an increased HDS activity for these solid state catalysts.

Other researchers $(27,30)$ have tried to link HDS activity to degree of sulfidation of the catalyst surface by examining the ratio of the S $2 p$ and Mo $3 d$ peak areas, and this value appears for our data in Table 3 . The cited works do not distinguish between the spin-orbit coupled states, so it is difficult to determine if the quoted ratios are the summation of these areas or the ratio of the most intense peaks, which would be the $\mathrm{S} 2 p_{3 / 2}$ and Mo $3 d_{5 / 2}$. We have used the ratios of the most intense peaks in Table 3. A ratio of 0.33 is obtained for all samples, except the unreacted $\mathrm{MoS}_{2}$, which Breysse et al. (30) interpret as complete sulfidation based on estimates of the sensitivity factors. However, we hesitate to draw this conclusion since a wide range of values ( 0.16 to 0.33 ) could be obtained depending on the source used for the sensitivity factors (31-33). What should be noted, however, is the increased B.E. of the Mo $3 d$ peaks in the nonstoichiometric samples relative to those of $\mathrm{MoS}_{2}$, as these values are shifted $0.88 \mathrm{eV}$ $\left(\mathrm{MoS}_{1.975}\right)$ and $1.0 \mathrm{eV}\left(\mathrm{MoS}_{1.95}\right)$ higher. This indicates that the Mo species undergo a less complete reduction as the sulfur content is decreased. Again, as pointed out previously, the possiblity of sample charging as cause for the small shift in binding energy cannot be ruled out. Surprisingly, the HDS 
activity of this sample is increased, implying that the HDS activity does not necessarily correlate with the degree of Mo reduction.

However, we may still infer that the surface of the nonstoichiometric and more catalytically interesting samples have been sulfided to a greater extent by examining the increase in the respective $S 2 p$ peak areas listed in Table 3. One possible reason for the larger increases (roughly 2.5 times the original values) in the nonstoichiometric materials relative to that of $\mathrm{MoS}_{2}(0.97$ and 1.4 times the original values) would be the oxygen overlayer that could not be removed from the $\mathrm{MoS}_{2}$ sample. Hence, the more active materials do undergo a more complete sulfidation.

Finally, it should be noted that the presence of the higher B.E. sulfur peak was suggested by Hercules and co-workers (26) to be linked to HDS activity. However, we did not find this to be a valid conclusion in our solid state catalyst system as the $\mathrm{S} 2 p_{1 / 2}$ : $2 p_{3 / 2}$ ratios did increase to 0.82 after $\mathrm{H}_{2} \mathrm{~S}$ / $\mathrm{H}_{2}$ exposure for the $\mathrm{MoS}_{2}$ sample, but the activity remained low. In contrast to this, the nonstoichiometric samples maintained a relatively constant ratio of roughly 0.70 but displayed a much greater HDS activity.

\section{CONCLUSIONS}

The results of this study indicate that changes in structure and morphology of the $\mathrm{MoS}_{2}, \mathrm{MoS}_{1.975}$, and $\operatorname{MoS}_{1.95}$ solid state materials used here may be followed by X-ray diffraction and electron microscopy. Both of these techniques were able to detect the increased disorder in the $2.7-\AA$ crystal plane, with disorder becoming more pronounced with decreased sulfur content. However, for the $\mathrm{MoS}_{1.975}$ sample, the disorder was surprisingly harder than anticipated to detect and image using high resolution electron microscopy. We have tentatively postulated that the initial removal of sulfur (0.6\% removed relative to $\mathrm{MoS}_{2}$ ) results primarily in a decreasing of the $c$ direction stacking order. The $2.7-\AA$ (101) plane is less affected, but the change can be detected.
Further removal of sulfur to yield $\operatorname{MoS}_{1.95}$ (1.3\% removed relative to $\mathrm{MoS}_{2}$ ) causes increased disorder in the (101) plane observable by HREM. The HDS activity of these materials correlated nicely with stoichiometry and also with the degree of defects and disorder created in the $2.7-\AA$ edge plane.

When the HDS activity was normalized per mole of Mo, 3 to 4 orders of magnitude difference in activity between $\mathrm{MoS}_{2}$ and $\mathrm{MoS}_{1.95}$ were observed. However, normalization using $\mathrm{O}_{2}$ or $\mathrm{CO}$ adsorption capacity brought the three catalysts within 1 or 2 orders of magnitude in activity. This leads to the conclusion that normalizing the activity based on $\mathrm{O}_{2}$ and $\mathrm{CO}$ adsorption is more meaningful than merely comparing activities based on overall Mo content. Surprisingly, nearly equivalent $\mathrm{O}_{2}$ and $\mathrm{CO}$ chemisorption uptakes were observed for the $\mathrm{MoS}_{2}$ and $\mathrm{MoS}_{1.975}$ samples, but a distinct difference in HDS activity was reported. We have tentatively postulated that this may indicate a sterically hindered pi-bonded thiophene mechanism on the $\mathrm{MoS}_{2}$ vs a more efficient sigma-bonded thiophene mechanism on the $\mathrm{MoS}_{1.975}$ controlling the surface reaction. However, it must be emphasized that this hypothesis requires more detailed kinetic analyses and surface science experiments before being confirmed or rejected.

The XPS studies indicate that the primary difference caused by introducing sulfur deficiencies into the $\mathrm{MoS}_{2}$ system is an increase in the signal intensity of both Mo and $S$. Judging from slight differences in $\triangle \mathrm{BE}$ between Mo $3 d_{3 / 2}$ and S $2 p_{1 / 2}$, the $\operatorname{MoS}_{1.975}$ sample appears to experience a less complete reduction of Mo during sulfiding as compared to the $\mathrm{MoS}_{2}$ catalyst. This was a very surprising result and more detailed studies using internal standards are necessary to obtain more accurate B.E. values. Sulfiding also caused a decrease in the band gap between the $\mathrm{S} 2 p$ energy levels in the $\mathrm{MoS}_{2}$ and $\mathrm{MoS}_{1.975}$ samples but had no effect on those levels in the $\mathrm{MoS}_{1.95}$ catalyst. The ability of the nonstoichiometric samples to dissociate $\mathrm{H}_{2}$ and entirely remove oxygen 
from the catalyst surface is most likely why the Mo and $\mathrm{S}$ species were found in greater abundance in these catalysts. This $\mathrm{H}_{2}$ dissociation capability was found to be characteristic of the more active samples. The specific phenomena linking increased catalytic activity with $\mathrm{H}_{2}$ dissociation and specific surface reaction mechanisms have not been established and further experimentation will be required to address these issues.

\section{REFERENCES}

1. Lipsch, J. M. J. G., and Schuit, G. C. A., J. Catal. 15, 179 (1969).

2. Gates, B. C., Katzer, J. R., and Schuit, G. C. A., "Chemistry of Catalytic Processes," Chap. 5. McGraw-Hill, New York, 1979.

3. Massoth, F. E., J. Catal. 36, 154 (1975).

4. Voorhoeve, R. J. H., and Stuiver, J. C. M., J. Catal. 23, 243 (1971).

5. Farragher, A. L., and Cossee, P., in "Proceedings, 5th International Congress on Catalysis, Palm Beach, 1972" (J. W. Hightower, Ed.), p. 1301. North-Holland, Amsterdam, 1973.

6. Hagenbach, G., Courty, P., and Delmon, B., J. Catal. 23, 295 (1971).

7. Delmon, B., Prepr. Am. Chem. Soc. Div. Pet. 22, 503 (1977)

8. Hagenbach, G., Courty, P., and Delmon, B., J. Catal. 31, 264 (1973).

9. Topsфe, H., Clausen, B. S., Candia, R., Wivel, C., and Mørup, S., J. Catal. 68, 433 (1981).

10. Wivel, C., Candia, R., Clausen, B. S., Mørup, S., and Topsøe, H., J. Catal. 68, 453 (1981).

11. Harris, S., and Chianelli, R. R., J. Catal. 98, 17 (1986).

12. Pratt, K. C., and Sanders, J. V., "Proceedings, 7th International Congress on Catalysis, Tokyo, Japan, 1980"' (T. Seiyama and K. Tanabe, Eds.), p. 1420. Elsevier, Amsterdam, 1981.

13. Ledoux, M. J., Maire, G., Hantzer, S., and Michaux, O., "Proceedings, 9th International Congress on Catalysis, Calgary, 1988" (M. J. Phillips and M. Ternan, Eds.), Vol. 1, p. 74. Chem. Institute of Canada, Ottawa, 1988.
14. Vissers, J. P. R., de Beer, V. H. J., and Prins, R., J. Chem. Soc. Faraday Trans. 1 83, 2145 (1987).

15. van der Kran, A. M., Cragé, M. W. J., Gerkema, E., Ramselaar, W. L. T. M., and de Beer, V. H. J., Appl. Catal. 39, L7 (1988).

16. van der Kran, A. M., Crajé, M. W. J., Gerkema, E., Ramselaar, W. L. T. M., and de Beer, V. H. J., Hyperfine Interact. 46, 567 (1989).

17. Villa-Garcia, M. A., Lindner, J., Sachdev, A., and Schwank, J., J. Catal. 119, 388 (1989).

18. Villa-Garcia, M. A., Lindner, J., Sachdev, A., and Schwank, J., Appl. Catal. 56, 281 (1989).

19. Sachdev, A., Lindner, J., Villa-Garcia, M. A., and Schwank, J., J. Solid State Chem. 87, 378 (1990).

20. Liang, K. S., Chianelli, R. R., Chien, F. Z., and Moss, S. C., J. Non-Cryst. Solids 79, 251 (1986).

21. Bachelier, J., Duchet, J. C., and Cornet, D., J. Catal. 87, 283 (1984).

22. Millman, W. S., Bartholomew, C. H., and Richardson, R. L., J. Catal. 90, 10 (1984).

23. Liu, H. C., Yuan, L., and Weller, S. W., J. Catal. 61, 282 (1980).

24. Bodrero, T. A., and Bartholomew, C. H., J. Catal. 84, 145 (1983).

25. Tauster, S. J., Pecoraro, T. A., and Chianelli, R. R., J. Catal. 63, 515 (1980).

26. Patterson, T. A., Carver, J. C., Leyden, D. E., and Hercules, D. M., J. Phys. Chem. 80(15), 1700 (1976).

27. Brinen, J. S., and Armstrong, W. D., J. Catal. 54, 57 (1978).

28. Okamoto, Y., Tomoika, H., Katoh, Y., Imanaka, T., and Teranishi, S., J. Chem. Soc. Chem. Commun., 47 (1978).

29. Cheetham, A. K., and Day, P., "Solid State Chemistry Techniques," Oxford Univ. Press, New York, 1988.

30. Breysse, M., Bennett, B. A., and Chadwick, D., J. Catal. 71, 430 (1981).

31. Wagner, C. D., Anal. Chem. 44(6), 1050 (1972).

32. Wagner, C. D., Riggs, W. M., Davis, L. E., Moulder, J. F., and Muilenberg, G. E., "Handbook of X-Ray Photoelectron Spectroscopy," Perkin-Elmer, Minnesota, 1979.

33. Perkin-Elmer Corporation, Physical Electronics Division, 5000 Series ESCA ES-02 Version Software 2.0, February 1988. 